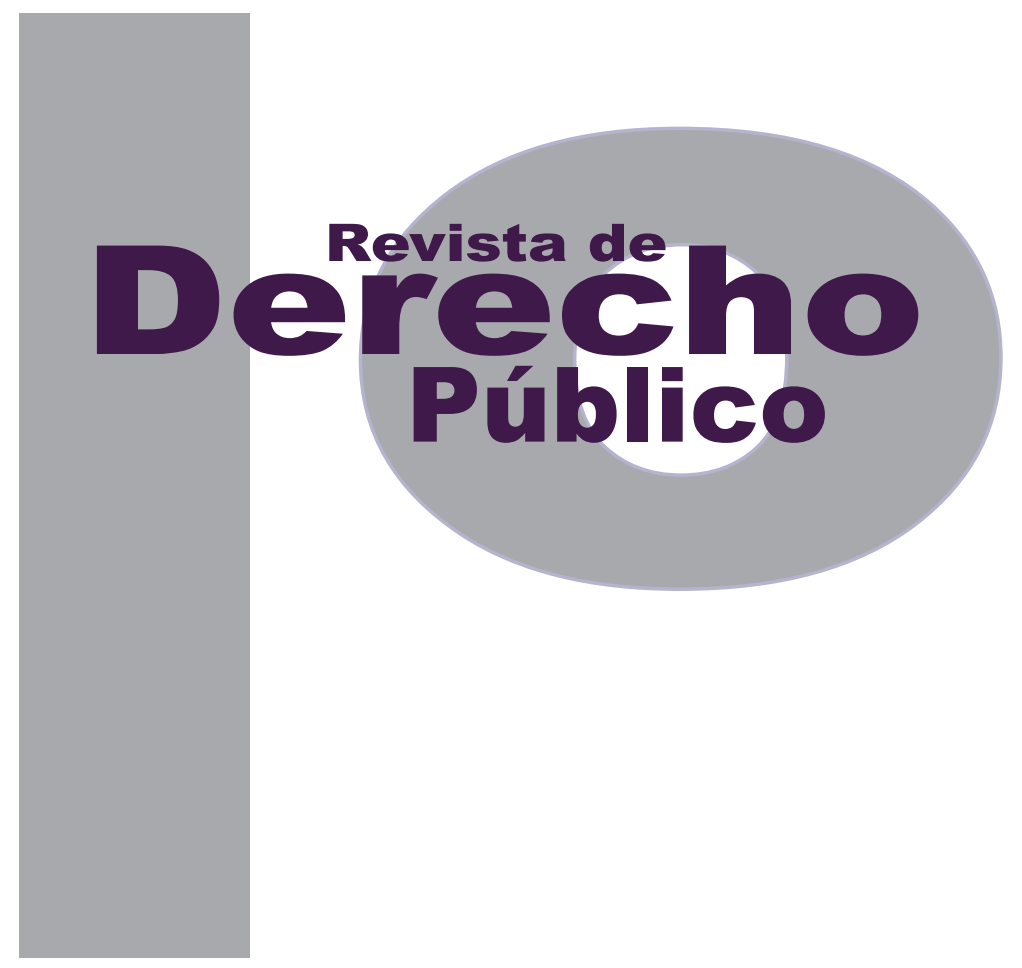

\title{
RECORDAR PARA OLVIDAR LA DESIGUALDAD DE GÉNERO
}

\author{
MARTA Grau
}

Universidad de los Andes

Facultad de Derecho

Revista de Derecho Público N. ${ }^{\circ} 31$

Julio - Diciembre de 2013. ISSN 1909-7778 


\title{
Recordar para olvidar la desigualdad de género*
}

\author{
Marta Grau**
}

\section{RESUMEN}

En este artículo me propongo visibilizar las representaciones y las relaciones de género en los discursos de la memoria del conflicto en Colombia a través de las producciones textuales del Centro de Memoria Histórica. Si la memoria tiene el potencial de dar cuenta de las injusticias del pasado para construir un futuro diferente, deberá tener también gran relevancia en la definición de los arreglos de género de las sociedades postconflicto. Si no se da voz a colectivos invisibilizados como las mujeres y no se muestra su sufrimiento desproporcionado en la guerra, se puede correr el riesgo de revictimizar y perpetuar la exclusión estructural. Sin embargo, si se evidencia la discriminación y se dignifica a las mujeres enfatizando su rol clave
In this article I propose to visualize the representations and gender relations in the discourses of memory of the conflict in Colombia through textual productions made by the Historical Memory Center. If memory has the potential to account for past injustices in order to build a new and different future, it may also have great relevance in defining gender relations in the post-conflict society. If the voice of women is not heard and their disproportionate suffering is not shown, there is a risk for memory to victimize again and perpetuate structural exclusion. However, if discrimination is explained and women are dignified by emphasizing its key role in building peace, memory can contribute to produce more equitable and fair relations between the sexes.

Cómo citar este artículo: Grau, M. (Diciembre, 2013). Recordar para olvidar la desigualdad de género. Revista de Derecho Público, 31.

Licenciada en Periodismo (Universitat Autònoma de Barcelona) y en Humanidades, Máster Internacional en Resolución de Conflictos (Universitat Oberta de Catalunya). Consultora en materia de derechos humanos y garantías para el Programa de las Naciones Unidas para el Desarrollo (PNUD). Correo: martagraurepullo@gmail.com 
en la construcción de la paz, la memoria puede contribuir a la construcción de relaciones más equitativas y justas entre sexos.

PALABRAS ClAVE: memoria, justicia transicional, guerra, género, poder, masculinidades, feminidades.
KEY WORDS: Memory, Transitional Justice, war, gender, power, male and female identity. 


\section{SUMARIO}

Introducción - I. COLOMBIA Y LA MEMORIA - A. La memoria persigue un futuro diferente - B. EI poder de la memoria - C. El género poderoso - II. ANALISIS - A. Transversalidad y lenguaje - B. Huyendo de estereotipos - C. Silencio a gritos - D. Memoria transformadora - III. CONCLUSIONES - Bibliografía. 


\section{Introducción}

En su andar decidido hacia la firma de acuerdos de paz, Colombia está dando relevancia a la memoria. Incluso, en medio de una guerra que todavía no cesa, viene realizando esfuerzos para elaborar y divulgar una narrativa sobre el conflicto armado que identifique los motivos del surgimiento y la evolución de los grupos armados ilegales. Así se define la razón de ser del Grupo de Memoria Histórica (GMH), que surge en el marco de la Comisión Nacional de Reparación y Reconciliación (CNRR), creada en 2005 por la Ley de Justicia y Paz (Ley 975 de 2005). Si bien la CNRR se extingue en 2011, esta primera apuesta por la memoria, lejos de quedar atrás, recibe un fuerte espaldarazo con la Ley de Víctimas y Restitución de Tierras (Ley 1448 de 2011). Esta norma crea el Centro de Memoria Histórica ${ }^{1}$, que asume el GMH y continúa y consolida la línea de trabajo iniciada.

En los primeros años, el Grupo apuesta por hacer memoria a partir de casos emblemáticos. En este artículo me planteo precisamente analizar algunos de estos casos, seleccionados a partir de un criterio temporal - uno por año desde el inicio del mandato del Grupo-y que en la parte Il (análisis) se identificarán con el nombre del lugar que recoge cada publicación, entre paréntesis, así: Trujillo. Una tragedia que no cesa, 2008 (Trujillo); El Salado. Esa guerra no era nuestra,

1 En la medida que el Centro asume el GMH, y que los textos analizados pertenecen tanto a antes como a después de esta modificación se opta por hablar de forma genérica del Grupo, entendiendo que hoy está integrado en el Centro de Memoria.
2009 (Salado); La Rochela. Memorias de un crimen contra la justicia, 2010 (Rochela); Mujeres que hacen historia. Tierra, cuerpo y política en el Caribe colombiano, 2011 (Caribe) y El Placer. Mujeres, coca y guerra en el Bajo Putumayo, 2012 (Placer). Esta decisión puede añadir a las conclusiones algún elemento de evolución respecto a la forma como se narran las relaciones de género. Sin embargo, reconozco que se trata de una selección aleatoria que puede suponer un riesgo para la generalización de hallazgos. En cualquier caso, mi objetivo no es hacer un repaso exhaustivo de toda la producción existente para dilucidar si el Grupo incorpora la perspectiva de género. Lo que pretendo es, a través de algunos ejemplos, percibir la forma como se dibujan las feminidades y masculinidades y su interacción en los discursos para preguntarme por el potencial transformador de la memoria en las relaciones de género en Colombia.

En este sentido, teniendo en cuenta que los discursos expresan significados y reproducen relaciones de poder, generan representaciones con visiones e imaginarios que terminan por tener incidencia en la realidad social y que, además, es a través del lenguaje que se construye la identidad de género (Scott, 1996), el método de investigación que consideré más adecuado para esta investigación es el conocido como ACD: análisis crítico del discurso (van Dijk, 1999). Normalmente, el ACD se ocupa de los discursos producidos por los grupos dominantes que son quienes tienen acceso a la manipulación y uso de estructuras de dominación. Sin embargo, en el presente trabajo planteo usar este método para los discursos de la memoria que preten- 
den, justamente, dar el poder de la producción de discursos a los/as tradicionalmente silenciados/as. A partir de ahí, lo que me interesa preguntar es: ¿visibilizar la desigualdad de género a través del discurso al igual que las iniciativas de resistencia a la dominación podría llevar a transgredir la tendencia que se le ha otorgado al texto en la perpetuación/legitimación de la injusticia? y por lo tanto, ¿se podría encontrar en los enunciados construidos por la memoria un mecanismo de acción política para transformar positivamente las relaciones de género?

Con la intención de buscar respuestas a estos interrogantes proyecto el análisis a partir de las siguientes categorías: transversalidad de género; interseccionalidad o múltiple discriminación; representación de la mujer/hombre como víctima, violento/a, pacífico/a; cambio de roles en la guerra y papel de la memoria en las relaciones de género.

Cabe señalar que este trabajo forma parte de un proyecto de investigación más ambicioso en el que pretendo analizar las relaciones de poder generizadas que entraña el discurso de la memoria en Colombia, su intencionalidad y su potencial incidencia en la conformación de los arreglos que existirán en el nuevo mañana que se está empezando a construir.

\section{COLOMBIA Y LA MEMORIA}

\section{A. La memoria persigue un futuro diferente}

La memoria histórica vuelve al pasado para permitir la construcción de un mejor futuro. En esa medida tal vez sea uno de los mecanismos más trascendentes de la llamada justicia transicional en el camino hacia la paz o la democracia.

Para las víctimas y la sociedad victimizada por un conflicto o una dictadura, la memoria forma parte del proceso necesario de recuperación. Las víctimas necesitan saber no solo qué pasó, sino también el porqué, así como conocer el paradero de sus muertos para poder empezar a superar su pérdida. Igualmente, las sociedades victimizadas, con un capital humano y un tejido social resquebrajados por la violencia, precisan conocer el pasado, que se esclarezcan los hechos de forma pública para procesar un duelo colectivo que parta del reconocimiento del sufrimiento de las víctimas y de la asunción de responsabilidades. Como señala Jelin (2001), los actores que luchan por definir y nombrar lo que ocurrió durante guerras o dictaduras, así como los que pretenden honrar y homenajear a las víctimas e identificar los/as responsables, visualizan su accionar como si fueran pasos necesarios para ayudar a que los horrores del pasado no se vuelvan a repetir.

La memoria tiene relevancia en la búsqueda de la no repetición, en la medida que puede contribuir al cambio cultural que requiere toda 
transición: conocer el pasado y horrorizarse con él puede provocar un sentimiento colectivo de rechazo a la violencia. La construcción de la memoria abre la puerta a la elaboración de una narrativa que permita la reescritura colectiva del pasado y las atrocidades que contiene, que elimine identidades y mitos violentos y facilite la recuperación o definición de nuevos mitos aptos para la coexistencia y la convivencia. Ofrece la oportunidad de contribuir a la formación de una nueva nación, una nueva comunidad o una nueva identidad étnica (Benavides, 2011). Permite identificar un compromiso nuevo entre el pasado y el presente (Jelin, 2001) donde el futuro sea más justo, estable y democrático (Bickford, 2007).

Por otro lado, la memoria ofrece información importante sobre la definición de los actores, las motivaciones, los marcos culturales y estructurales, así como los impactos y los costos de la violencia, y ello debería servir para aumentar la capacidad institucional y social en la adopción de medidas más acertadas para la prevención de las violencias, para contribuir a detenerlas y para evitar que estas se perpetúen.

\section{B. El poder en la memoria}

La memoria no es ajena al poder y a las relaciones de superioridad o subordinación que este imprime. Depende de cómo hayan sido las condiciones de los acuerdos de paz o de transición a la democracia, y de las relaciones de poder que puedan permanecer después de estas. Los procesos de construcción de memoria pueden ser utilizados con beneficios partidistas quedando así desvirtuados y obteniendo resultados perversos. El lado vencedor puede usar la memoria para reescribir la historia en su favor y borrar de ella el lado vencido. También puede manipular los imaginarios y presentar a la parte vencida como victimaria para justificar las violaciones a los derechos humanos como actos de legítima defensa. Estos mecanismos pueden convertirse en instrumentos de nueva violencia simbólica que reproducen el ocultamiento y la opresión (Benavides, 2011).

Los procesos de memoria sufren, como el resto de mecanismos de justicia transicional, la tendencia dominante de ser promovidos por los centros de poder, en muchos casos por la cúpula de los gobiernos, y en ocasiones terminan por privilegiar un enfoque nacional centralizado y vertical marginando las perspectivas locales y rurales, las visiones diversas y plurales que puedan existir en la sociedad e incluso las experiencias de las propias víctimas. Para Guzmán y Uprimny (2010, p. 10) esta inclinación puede tener una explicación razonable: “las sociedades en transición usualmente atraviesan por rupturas institucionales y societarias de tal entidad que la única posibilidad de lograr una transformación rápida es a través de medidas centralizadas, con fuerte respaldo político y con grandes recursos económicos". Señalan que para garantizar que los esfuerzos de transición fueran alcanzados en una sociedad con estructuras democráticas débiles, se ha tendido a fortalecer la acción pública unificada, centralizada y con pretensiones de universalidad. Sin embargo, la adopción de esta opción, como señalan estos autores, presenta serias debilidades. 
Es fácil deducir que en los casos en que el Estado fue uno de los principales perpetradores de violaciones a los derechos humanos y donde no se han dado transformaciones profundas en las relaciones de poder en su interior, el Ejecutivo tenderá a responder de forma más bien limitada a las demandas de verdad y reconstrucción de los hechos del pasado. Es en las borraduras y olvidos a las que se refiere Jelin (2001) donde se dan actos políticos voluntarios de destrucción de pruebas y huellas con el fin de promover olvidos selectivos.

Las élites juegan también un papel relevante en los procesos de transición, y en ocasiones se ha privilegiado su atención en detrimento del resto de la población, cosa que perjudica el fortalecimiento de la democracia. Es decir, la justicia transicional y la reconstrucción de un pasado común pueden fortalecer la democracia, en la medida que transforma la relación de enemigos a adversarios y promueve la gestión de las diferencias dentro del medio político. Pero, por otro lado, puede tener resultados no deseados si limita esa construcción de "lenguaje común" a las élites. Así ocurrió en Argentina en la posibilidad de diálogo entre radicales, peronistas y Fuerzas Armadas o en Sudáfrica entre la clase política blanca y la clase política negra (Lefranc, 2007).

La exclusión de las víctimas es prácticamente un absurdo en un ejercicio de construcción de memoria. Sin embargo, esta se da cuando los procesos de construcción de memoria no parten de la voluntad de superar el conflicto o la opresión y sus causas, o cuando no parten de la necesidad de dignificación de las víctimas -no entendidas como un colectivo compacto u homogéneo sino percibido desde su máxima pluralidad y diversidad-y de considerarlas protagonistas.

Por la tremenda importancia que tiene, la memoria debe cuidarse desde el mismo proceso para no incurrir en contradicciones con su objetivo: un futuro en paz y en democracia. En ese sentido, el proceso de construcción del pasado y la memoria debe diseñarse y llevarse a la práctica con la premisa de garantizar la mayor transparencia y participación posible (Bickford, 1999; Naidu, 2006; Guzmán y Uprimny, 2010).

\section{El género poderoso}

En muchos casos (Perú, Colombia), la mayoría de las víctimas de las graves violaciones a los derechos humanos pertenecen a colectivos tradicionalmente discriminados, excluidos, marginados o en situación de vulnerabilidad. Me refiero a las mujeres, las niñas y los niños, los pueblos indígenas o las comunidades afrodescendientes, así como la población campesina o rural, entre otros ${ }^{2}$.

El deber de la memoria es reconocer y hacer público que estos grupos han sido víctimas de la violación sistemática de sus derechos y que su condición de víctimas se ha sumado a una situación injusta existente en la sociedad anterior

\footnotetext{
2 En algunos casos se trató de determinados partidos políticos o grupos discriminados por razones étnicas, de orientación sexual, ideologías o religiones.
} 
al estallido de la guerra. Si no se reconoce ese sufrimiento desproporcionado y no se da la voz principal a estos colectivos en los mecanismos de memoria se corre el riesgo de revictimizar y perpetuar la exclusión estructural que favoreció la violencia.

Cada uno de estos colectivos tiene una forma particular y específica de interpretarse a sí mismos y de comprender el pasado. Igualmente, tienen necesidades y capacidades diferentes para enfrentar el duelo, y particulares visiones sobre lo que es o debe ser la memoria. Como señala Wills (2009, p. 45) "desde la mirada de género, mujeres, hombres y diversidades sexuales leen de distinta manera el pasado y escogen huellas disímiles para construir sus memorias". Sus miradas y sus voces no pueden ser silenciadas en ningún ejercicio de memoria que se considere real. Las narrativas y los relatos del pasado deben servir, justamente, para reconocer que las mujeres y otros sectores tradicionalmente discriminados tienen los mismos derechos y la misma capacidad para opinar que los hombres blancos, heterosexuales, propietarios y educados que, desde su visión de superioridad, han construido históricamente los discursos y han sido los protagonistas de la definición de los proyectos de nación.

La mirada de género tiene la capacidad de preguntarse por la diferente y desigual distribución del poder entre las mujeres y los hombres, de ver de forma distinta la realidad y su problemática. Ayuda finalmente a examinar diferente viejos problemas con la pretensión de "desmantelar las estructuras de desigualdad" (Rayna Reiter, citada en Lamas, 1996). Involucra, en palabras de Cifuentes (2009), la opción de contestación, de transformación de ordenamientos injustos, asimétricos e inequitativos, desde una clara comprensión de su potencia estructural, de su arraigo cultural y de los mecanismos sutiles y abiertos de poder a través de los cuales se legitiman y buscan su perpetuación.

\section{ANÁLISIS}

\section{A. Transversalidad y lenguaje}

Los textos del Grupo de Memoria Histórica, en general, evidencian una preocupación por las dinámicas de género y por evitar la perpetuación de la desigualdad estructural entre los hombres y las mujeres. Sin embargo, los resultados de los diferentes casos emblemáticos seleccionados para este análisis arrojan resultados diferentes en tan loable y necesario esfuerzo.

El lenguaje sensible al género se consigue prácticamente de forma exclusiva en aquellas compilaciones dedicadas de forma específica a la situación de las mujeres (Placer, Caribe). En los otros informes su uso es más bien irregular y demuestra cuán arraigada y naturalizada está la generalización del masculino como sinónimo del género humano. Si bien todavía los diccionarios aceptan esa generalización y, por lo tanto, lingüísticamente hablando puede que no estén incurriendo en un error, sí es una omisión grave desde el punto de vista político en autores/as que reescriben el pasado para mejorar el futuro. Si en ese ejercicio no se nombra lo silenciado 
por siglos, tampoco existirá o será relevante en la nueva sociedad que configure el postconflicto.

De todos modos, tal vez más importante que recordar mencionar el femenino en todas las construcciones gramaticales es el cuidado en el contenido. En todos los volúmenes consultados se señalan aspectos diferenciales de género tanto en los diagnósticos como en la narrativa de las acciones emprendidas. Sin embargo, en algunos análisis el esfuerzo permea todo el texto, en otros se concentra en capítulos exclusivamente dedicados a las mujeres o a las relaciones de género, y esa perspectiva se diluye en el resto de secciones.

\section{B. Huyendo de estereotipos}

En general, el discurso de la memoria huye a la estereotipación de lo que es ser mujer y de lo que es ser hombre. Es decir, se intenta no caer en las etiquetas de mujer pacífica y/o víctima y hombre violento, por cuanto se relacionan con atributos impuestos a cada sexo: la víctima es débil, dependiente y frágil; el combatiente es violento e insensible. Estas construcciones mentales tradicionales han sido ya ampliamente problematizadas por la academia feminista.

De un lado, la supuesta naturaleza pacífica de las mujeres no es aceptada por gran parte de la literatura (El Jack, 2003; Byrne, 1996; Moser y Clark, 2001; Kelly, 2011, citadas en Truñó, 2010) porque despolitiza las mujeres y termina por perpetuar las relaciones de dominación que parecen incuestionables al ser dadas por la naturaleza (Wilches, 2012). Es, finalmente, un estereotipo que no es válido desde una mirada de género y feminista.

En los casos emblemáticos del Grupo aparecen múltiples formas de reconocer la representación de la feminidad: mujeres víctimas directas o indirectas, mujeres lideresas, mujeres armadas, entre otras. Además, las fronteras entre esas identidades pueden resultar difusas en ocasiones y algunas mujeres pueden estar representadas por varias identidades al mismo tiempo o pueden pasar de una a la otra a lo largo de historias de vida desarrolladas en marcos de violencia. En un conflicto tan complejo como el colombiano, las identidades pueden ir mutando de acuerdo con el desarrollo de este, con los procesos que viven las mismas mujeres y con la etapa de la vida en que se encuentran.

Por ejemplo, en Trujillo se identifican tres tipos de eventos violentos donde aparecen mujeres: mujeres atacadas por sus vínculos afectivos 0 de consanguinidad; mujeres tratadas como emblemas de identidades colectivas perseguidas $y$ mujeres que son objeto de violencia por haberse atrevido a transgredir el rol femenino tradicional.

En los discursos de la memoria encontramos, efectivamente, un gran número de víctimas que se convierten en tales por ser esposa de, madre de, etcétera. En Placer se señala que las "mujeres eran vistas como parte del entorno afectivo del enemigo que había que destruir para humillar, desmoralizar y herir" (Grupo de Memoria Histórica, 2012, p. 134). En este caso, las mujeres no se visibilizan tanto por lo que son sino por 
sus relaciones con los demás (particularmente los hombres).

A través de algunos testimonios o comentarios recogidos, especialmente en la presentación de las viudas de La Rochela, se refuerza el estereotipo de feminidad débil, propensa al dramatismo y desprovista de ruta y horizonte ante la ausencia de la figura masculina.

En cuanto a las agresiones por ser emblemas de identidades colectivas perseguidas se encuentran también algunos casos donde se las ataca por ser pariente de. Es la situación de la sobrina del padre Tiberio, en Trujillo, donde agrediendo la mujer se quiere atacar la ideología y la acción política del hombre. En este caso, el pecado del padre Tiberio fue precisamente empoderar a las mujeres.

Muy interesante es, por otro lado, que se destaquen y valoren las identidades transgresoras. En las obras publicadas por el Grupo aparecen mujeres que abandonan su rol tradicional de sumisión frente a los hombres y frente al poder, representado por las armas, y muestran su disconformidad sin tapujos. En Trujillo, por ejemplo, se presenta a Esther Cayapú, quien enfrentó la policía cuando agredió a su hijo, y a María Elida Gómez, asesinada por hacer comentarios críticos en presencia de la Fuerza Pública.

Del relato de El Placer se desprende la conclusión que los/as paramilitares asociaron a la mujer con la reproducción biológica, lo pasivo, la esfera privada, lo débil, la sumisión, reforzando así la lectura tradicional y patriarcal de la fe- minidad, con la consecuencia de que quien se saliera de ese estereotipo era considerada una identidad transgresora. Así, "atreverse a enfrentar a los armados era sinónimo de guerrillera" (GMH, 2012, p. 146).

A esta categoría de identidades transgresoras que subvierten roles tradicionales pertenecerían también las tipificaciones planteadas en Placer relacionadas con las formas, motivos o razones por las que las mujeres son perseguidas en el marco del conflicto: i) mujeres informantes y ii) mujeres relacionadas (de forma falsa o verdadera) con la guerrilla o sus redes.

En el primer caso, los/as paramilitares asumían que "una mujer con un hijo en la guerrilla era un canal directo de información para el bando opuesto [...] con lo que se construyó una analogía entre ser madre y ser "informante" (GMH, 2012, p. 135). De nuevo el rol de madre o el parentesco supone una forma forzada para las mujeres de verse involucradas en la guerra, como pasaba con las mencionadas identidades transitorias.

Igualmente, como se relaciona en el segundo caso, la supuesta militancia en la subversión ha puesto en peligro las mujeres de Colombia. En Placer podemos descifrar un ejemplo de estigmatización a través de un testimonio que hace referencia a la muerte de Miriam: "muchacha trabajadora y buena vecina, la mataron. "A vos te estamos buscando', ya que los paras decían que era vocera de la guerrilla" (GMH, 2012, p. 135). 
En ocasiones, sin embargo, las mujeres aprovecharon su rol tradicional de género para subvertirlo y de esta manera engañar al enemigo y asumir un nuevo rol emancipador como el de proteger al hombre, contrariando el papel tradicionalmente atribuido a este en cuanto a protección de la familia. De esta subversión del rol tradicional de las mujeres encontramos un ejemplo en Placer, donde bajo el supuesto que la guerra es cosa de hombres las mujeres actuaron "tácticamente como escudos humanos" (GMH, 2012, p. 294) acompañando a sus esposos a todas partes en el entendido que "andar con la familia a cuestas blindaba a los pobladores de ser asociados con la guerrilla" (GMH, 2012, p. 295).

En los textos en estudio se recogen múltiples casos de mujeres que transforman su identidad justamente por su condición de víctima. Para los arreglos de género es interesante esa apreciación. Y es que ser víctima no debería traducirse en una nueva forma de considerar a las mujeres como seres necesitados de protección, frágiles, vulnerables, dependientes y sin capacidad de agencia (Truñó, 2010). Para huir de esta equiparación algunas feministas rechazan la identificación de "víctima” (Bertain y Riera, 1992; Pipper, 2005, citadas en Truñó, 2010) porque piensan que limita su autonomía y las considera portadoras de una marca. Según Zajovic (2005) el patriarcado impone a las mujeres el rol de víctimas para quitarles la posibilidad de ser ciudadanas activas. Sin embargo, autoras como Ochy Curiel (2006, citada en Truñó, 2010) consideran que lo que es antifeminista es la victimización pero no la categoría de "víctima". Según ella, reconocerse víctima ofrece la posibilidad para la intervención política, la democratización de la experiencia y la transformación de las relaciones de poder y de género.

En el discurso de memoria generado por el Grupo se perciben múltiples ejemplos donde las mujeres se fortalecen y transforman sus roles tradicionales justamente por el hecho de ser víctimas, por el hecho de haber visto sus vidas atravesadas por la violencia. La misma lucha por la memoria ha contribuido a su empoderamiento. En Trujillo son relacionadas con las luchas que las víctimas sobrevivientes han tenido que emprender para que el Estado y la opinión pública reconozcan la verdad y para que los crímenes no queden en la impunidad. En estos procesos, algunas víctimas han realizado viajes políticos que les han permitido desarrollar competencias, ampliar horizontes y liderar iniciativas que defienden los derechos humanos. En el mismo orden de ideas, se señala en Caribe que "a raíz del asesinato de los hombres en el marco del conflicto, ellas pasan a un lugar de liderazgo en el espacio público como reclamantes de derechos, no solo en su calidad de ciudadanas sino también de víctimas del conflicto" (GMH, 2011, p. 127).

De esta manera, el discurso reescribe un pasado donde las mujeres asumen protagonismo. Debido a la guerra y a su condición de víctimas, las mujeres se ven obligadas a enfrentar roles diferentes, esto es, en lo productivo y político (reclamos de justicia por sus muertos y por los derechos de los y las sobrevivientes) lo que las ubica en nuevos escenarios con distintos retos. Algunas "salen adelante y descubren potencia- 
les que ellas mismas albergaban y que ni siquiera sospechaban" (GMH, 2008, p. 215).

Las representaciones de las masculinidades, en algunos casos, subvierten también sus formas estereotipadas en los casos emblemáticos analizados. En varios de los informes se hace mención a la forma diferenciada como hombres y mujeres enfrentan la catástrofe y se reconoce la dificultad que tienen los primeros con la masculinidad hegemónica impuesta que, según Gilmore (2008), se caracteriza por las "tres P": protección, provisión y potencia.

Es novedoso plantear también la naturaleza de víctimas de la violencia que les ha correspondido a los hombres en la guerra, por estar en la primera línea de fuego, por ser los que resultan en mayor número asesinados o heridos durante los enfrentamientos armados y por perder en esos mismos escenarios también a hermanos e hijos. Sin embargo, en el discurso hegemónico se ha explorado poco esta condición difícil para ellos. De hecho, en estas circunstancias se les presenta también como "héroes masculinos" (Moser y Clark, 2001, citados en El Jack, 2003).

No reconocer ni considerar a los hombres como víctimas es silenciar una realidad de género en los conflictos. Efectivamente, admitir esa realidad contribuye a debilitar un mito negativo para la equidad de género y la búsqueda de la no violencia y la paz como imagen de la invulnerabilidad masculina (Segal, 2008).

En el discurso de la memoria analizado se reconoce la dificultad que tienen los hombres con
Ios patrones culturales imperantes. Por ejemplo, en Trujllo, una joven líder explica cómo ella soporta mejor la pérdida del papá asesinado porque "tiene licencia para llorar y ser 'amiga' de su mamá con quien recuerda y elabora el duelo", y reconoce que sus hermanos no han podido elaborar el duelo por los imperativos que la cultura impone sobre la masculinidad (si eres hombre, no llorarás) y por haber quedado sin una figura masculina (el padre asesinado) que guíe a los hermanos en su recuperación. Igualmente señala que ellos sufren, además, la culpa por estar infringiendo otro precepto cultural: el del hombre proveedor que garantiza la supervivencia de la estirpe. Adicionalmente, se sienten en deuda con la madre, ya de edad, que debe seguir trabajado para sostenerles (GMH, 2008, p. 223).

De la misma forma, los/as autores de las narrativas en estudio ponen de relieve que la situación de pérdida es peor asumida por los hombres, refiriéndose a las estadísticas que muestran que son más los hombres (sobretodo mayores) que enferman y mueren de tristeza.

Si bien con alguno de los ejemplos presentados se pueden vislumbrar tal cual efectos positivos de los conflictos en la transformación de las relaciones de género, tampoco hay que olvidar que sobre todo el paramilitarismo -pero también las guerrillas- imponen en la sociedad las versiones más estereotipadas de la feminidad y la masculinidad. Los imaginarios paramilitares estigmatizan a los hombres como guerrilleros a partir de representaciones de género basadas en la apariencia física, por ejemplo, “desarregla- 
do" y "mechudo" (GMH, 2009, p. 143) o el carácter: "los hombres debían ser viriles". De esto se desprende que no llevar el pelo corto o no ser agresivo convierte a los hombres en sospechosos, por lo que no se permite espacio ni oportunidad a nuevas formas de masculinidad.

Sin embargo, en los textos se recogen algunos ejemplos de hombres que empiezan a desprenderse, por lo menos en la intimidad, de esa foto fija de lo que supuestamente es ser hombre. Se percibe en Caribe (GMH, 2011, p. 142) en el testimonio de una de ellas:

He tenido una relación con hombres que, sí, una reconoce que hay gente machista pero dentro de los machistas también hay hombres buenos, hombres que uno puede dialogar con ellos, hombres que son comprensivos con uno y que sí veo que nosotros no los podemos descartar porque nosotros no podemos vivir sin los hombres ni los hombres sin nosotras. Conforme hay hombres malos hay mujeres malas y perversas porque también las he conocido...

\section{Silencio a gritos}

Los gritos de la memoria también pueden estar llenos de silencios. La exclusión de las mujeres puede ser tan fuerte y tan interiorizada que ni siquiera aparece en las propias narrativas elaboradas por ellas. La forma como cada persona recuerda, interpreta y reinterpreta los hechos del pasado no puede desligarse del contexto en el que vive, de su rol en la sociedad, de sus creencias ni de su moral. Como señala Wills (2009), los recuerdos no son ajenos de las memorias colectivas y estas son a la vez produc- to de distintas y múltiples "mediaciones". Los testimonios de las víctimas, por lo tanto, no son extraños a los principios de la sociedad patriarcal ni a los prejuicios sobre orientación sexual, pertenencia étnica, entre otros, imperantes en el entorno.

El reconocimiento que hace el Grupo de esta situación es clave. De hecho, en Trujillo se confiesa que la toma de conciencia de la situación de "machismo" anterior a la guerra se despierta entre las víctimas con las preguntas de la coordinadora de los ejercicios de memoria. Una vez estirado el hilo, los y las profesionales de memoria extraen de los testimonios la definición de la población antes de la masacre: una situación de machismo apoyada por el ejercicio de la violencia física, donde las mujeres eran explotadas bajo trabajo doméstico o en el campo desde niñas, se les imponía marido en edades muy tempranas, algunos padres se mostraban decepcionados cuando nacía una niña y podían hasta llegar a expresarles aversión por el solo hecho de ser mujeres (GMH, 2008, p. 219).

\section{Memoria transformadora}

Ello supone que si las personas que recogen los testimonios tienen conciencia de género y son capaces de llevar las entrevistas hacia el terreno de la identificación de las relaciones de poder existentes entre mujeres y hombres, y el reconocimiento de la violencia de género -entre ellas, la sexual dentro y fuera del conflicto-, el ejercicio de la memoria podrá tener un poder transformador en la vida de las personas y las comunidades, en la medida que el recono- 
cimiento de una situación viciada es el primer paso fundamental para definir herramientas para superarla.

La sociedad postconflicto no puede tener como meta retroceder a la sociedad preconflicto donde la vida de las mujeres estaba inserta en prácticas de dominio masculino violento.

A partir de un ejemplo en Caribe (GmH, 2011, p. 158) se pone blanco sobre negro la aspiración del Grupo:

$\mathrm{MH}$ espera que la reconstrucción de la trayectoria de la vida de Margarita, con sus luchas, vejaciones y coraje, sirva para inspirar políticas que garanticen para las mujeres campesinas de este país una vida libre de violencias, violencia infringida por 'manos amigas', así como por actores armados; y su acceso a una propiedad rural acompañada de la oferta de un crédito y asesoría técnica para que puedan cumplir el sueño de ofrecerse y ofrecerles a los suyos una vida digna.

De esta manera, la memoria se valora como un mecanismo que contribuye a la sanación colectiva a través de la experiencia individual y posee la capacidad de incidencia en la transformación estructural colectiva hacia un futuro mejor $y$ más digno.

\section{CONCLUSIONES}

En los discursos de la memoria histórica de Colombia planteados por el Grupo me propuse buscar si a través de las palabras se reprodu- cían relaciones discriminatorias de género cayendo así en la perpetuación de la desigualdad; si el lenguaje utilizado puede tener relevancia en la sustitución de imaginarios sobre identidades masculinas violentas y mujeres pacíficas por otros no estereotipados que enmarcan las mujeres y los hombres con activo potencial para la paz; y si la visibilización a través del texto de las estructuras de poder machistas existentes antes y durante la guerra, así como los cambios de roles provocados por el conflicto podían tener un potencial para transformar las relaciones de género futuras.

En general, el discurso del Grupo no deja por fuera el relato de la desigualdad de género e incluso provoca la toma de conciencia por parte de las mujeres a partir de la propia narración de su pasado y de su experiencia. A través de los casos emblemáticos analizados se evidencia la contribución del Grupo en cuanto a sacar a la luz las relaciones discriminatorias de género existentes en Colombia. El reconocimiento es el primer paso para la transformación tanto de las actitudes y comportamientos individuales y colectivos como de la acción del Estado y la priorización de políticas que remedien la desigualdad del pasado.

Los problemas de género no se presentan como consecuencia del conflicto, al contrario, se hace mucho énfasis en que la discriminación y la desigual en la distribución de poder entre mujeres y hombres existían antes del ruido de las armas. La violencia contra las mujeres no se inicia tampoco con los actores armados. 
Poner esta situación de relieve es también fundamental porque plantea que el objetivo de la memoria no será volver al punto de inicio sino transformar esa situación de partida desfavorable para más de la mitad de la población del país.

También es de resaltar que la inclusión de la mirada de género no se limita ni concentra en temas de violencia sexual, como ha ocurrido en varios de los esfuerzos realizados por anteriores comisiones de la verdad cuando han querido plasmar esta perspectiva. Las relaciones de género se plantean como algo mucho más complejo y con impacto en cualquiera de las dinámicas presentadas.

Las representaciones de la feminidad y la masculinidad se exponen a partir de una gran pluralidad de formas de ser mujer y de ser hombre en el marco del conflicto colombiano. Las mujeres son víctimas, son violentas, transgreden sus roles tradicionales y también Iloran. Los hombres son víctimas, son violentos, transgreden sus roles tradicionales y también Iloran.

Por la naturaleza del discurso, se entiende que la mayoría de las mujeres que aparecen sean víctimas. En ocasiones, como se vio con las viudas de La Rochela, se refuerza la condición de vulnerabilidad de las mujeres al presentarlas como "desconsoladas y desconcertadas" sin saber "qué papel jugar" (GMH, 2010, p. 233). Sin embargo, en general, se percibe un esfuerzo por presentar a las mujeres víctimas desde la reivindicación de la dignidad y no desde la desposesión de la capacidad para agenciarse.
Cabe decir también que, en alguna ocasión, los discursos caen un poco en el enaltecimiento de la identidad femenina como pacífica y predestinada al bien. Aunque es cierto que se menciona muy de pasada la presencia de mujeres en las filas armadas, se hace poco énfasis en esa dimensión de las identidades femeninas. La explicación puede encontrarse en que los ejercicios de memoria pretenden dignificar a las víctimas y no justificar a los/as victimarios/as ni generar empatía con ellos/as tengan el sexo que tengan.

Si bien es cierto que se hace hincapié en la afectación que supone la dualidad de ser víctimas y de ser mujeres a la vez, en los discursos se olvidan énfasis importantes en otros factores de discriminación u opresión como la clase, la edad, la etnia o la orientación sexual. Dar esa relevancia de forma más explícita sería necesario y pertinente para una erradicación colectiva de las estructuras desiguales de poder que conlleven a una sociedad efectivamente más justa e igualitaria. El despojo de los factores de discriminación debe ser integral, por lo que no tendría sentido que una mujer dejara de ser excluida por ser mujer pero en cambio siguiera siendo estigmatizada por el color de su piel.

Por otro lado, es muy significativo que la mayoría de los perfiles de mujeres presentadas no se quedan en una foto fija, sino que se muestran en un proceso, en un camino evolutivo hacia su empoderamiento. De ahí la respuesta sobre los efectos colaterales (en este casos, positivos) de la guerra sobre la emancipación de las mujeres. Evidenciar estos viajes políticos de las mujeres en discursos no específicamente dirigidos 
a ellas contribuye a la toma de conciencia por parte de los hombres y el resto de la sociedad. El desmonte de argumentos para el rechazo al empoderamiento de las mujeres puede contribuir a erradicar este tipo de actitudes contrarias a la satisfacción de sus derechos. En los textos, de hecho, se plantean las tensiones que esa emancipación supone en los hombres y en las representaciones tradicionales de la masculinidad.

Esas presiones se ven también en las filas de los grupos armados que perpetúan estructuras patriarcales y de dominación. En múltiples ocasiones se hace referencia en los libros al obstáculo que supone la guerrilla, y sobretodo el paramilitarismo, en la transformación de las relaciones de género tradicionales en vínculos más justos y equitativos.

Si bien los actores armados se mencionan prácticamente siempre y de forma genérica o particular en masculino, tampoco la presentación de identidades masculinas se reduce a la violencia. También se recogen figuras transformadoras como la del padre Tiberio y víctimas como los viudos de La Rochela, aunque se les presente fuertes (por lo menos externamente), con iniciativa y capaces de enfrentar la responsabilidad de sacar de la desesperación y el desconcierto a las mujeres que han corrido la misma suerte que ellos en la masacre.

Con estas conclusiones no pretendo dar créditos inmerecidos a la guerra ni plantear que el conflicto es la única forma de conseguir la transformación de los roles tradicionales de la feminidad y la masculinidad. Sin embargo, sí quiero evidenciar que la guerra subvierte esas relaciones y en ocasiones proporciona a las mujeres oportunidades positivas para su emancipación. La sociedad debe estar preparada para mantener en el tiempo esos logros gestionando las tensiones y las transformaciones que ello suponga en la vida de los hombres.

Con ello pretendo llamar la atención sobre el hecho que la memoria no solamente debe verse como un mecanismo que sirve a las víctimas para empezar procesos de duelo y por lo tanto de sanación o recuperación; tampoco como una forma de reparación. Propongo mostrarla como una oportunidad para transformar los errores del pasado, incluso aquellos cometidos antes de la aparición del primer disparo en el marco de un conflicto armado. Su misión no debe limitarse, por lo tanto, a recuperar la verdad y lo perdido ni en volver al estado de cosas existente antes de la guerra. La memoria debe ir más allá y propender por una modificación estructural de las condiciones de opresión que agravaron la afectación del conflicto en la vida de las mujeres. La memoria tiene potencial para definir un nuevo sistema de valores que permita la coexistencia pacífica en todas las esferas de la vida humana. Pero para que ese propósito llegue a buen puerto, debe estar preparada para sortear trampas que puedan hacerla naufragar en nuevas oleadas de revictimización y opresión. Para evitarlo debe cuidarse mucho tanto desde el discurso como desde el mismo proceso de elaboración.

Una forma imprescindible para sortear trampas es, a mi modo de ver, la incorporación de 
una perspectiva de género $-\mathrm{y}$, desde mi punto de vista, basada en el feminismo de la diferencia - en todos y cada uno de los procesos de memoria histórica. Para ello es fundamental contar con personas sensibilizadas en todo el ejercicio de memoria, esto es, quien planifica, quien escucha, quien transcribe o quien escribe para evitar que el sistema de valores patriarcal impregne y sesgue la selección de los temas y su abordaje. Todas las personas que intervienen en la producción de estos discursos de memoria, incluidas las víctimas y quienes dan testimonios, están inmersas en una cultura machista y han naturalizado e interiorizado infinitos perjuicios. Para luchar contra ese lastre hay que hacer un tremendo esfuerzo y una toma de conciencia colectiva, de modo que, en el resultado, los discursos hagan visible tanto el sufrimiento padecido por las mujeres como su capacidad de agencia.

Tampoco hay que caer en la ingenuidad de pensar que la inclusión de las mujeres en las narrativas del pasado producirá cambios inmediatos y mágicos. Igualmente, tampoco es suficiente que los centros de poder cedan en la incorporación de las mujeres en el discurso sin una traducción real y práctica. Sin embargo, no hay duda de que si una comisión de la verdad, un centro o un museo de la memoria no logra la incorporación efectiva de la perspectiva de género su misión será incompleta. No solamente se perdería una oportunidad para contribuir a transformar la desigualdad histórica entre hombres y mujeres, sino que se estaría dando un espaldarazo - seguramente indirecto e involuntario- a la perpetuación de la dominación mas- culina, blanca y heterosexual, tan presente en el origen de múltiples conflictos y violencias.

Si el objetivo de la memoria es la reescritura colectiva del pasado para eliminar identidades y mitos violentos, esta no puede dejar por fuera la violencia generada contra las mujeres. Tampoco puede dejar de mencionar y resaltar el rol de las mujeres en la revisión de lo que pasó y que ya había sido silenciado en la historia oficial. Igualmente, la forma como las mujeres aparecen en las nuevas narrativas no puede reproducir los roles estereotipados que han justificado esa violencia durante siglos.

Si la memoria pretende entender los patrones de violencias para que el Estado pueda impulsar medidas más acertadas de carácter integral para prevenirlas, detenerlas y evitar que se perpetúen, el análisis de actores, motivaciones, marcos culturales, estructurales e interpretativos no puede dejar por fuera un estudio profundo sobre las relaciones de género. Sin ello, las respuestas no serán adecuadas a las necesidades y problemáticas ni permitirán revertir tendencias y contribuir así a las garantías de no repetición de las violaciones a los derechos humanos de las mujeres, sin lo cual no se puede hablar de paz positiva, real ni mucho menos como una condición sostenible y duradera.

Si la memoria tiene la voluntad de permitir un nuevo futuro sin violencia debe partir de un proceso incluyente, transparente y participativo; debe propender por una transformación estructural y cultural que elimine las discriminaciones y las opresiones del pasado. En esa medida tie- 
ne la responsabilidad de evidenciar la situación de las mujeres y el esquema patriarcal. La memoria ofrece por lo tanto la oportunidad de revisar el pasado $y$, de un lado, generar un nuevo sistema de valores y, del otro, armar una arquitectura institucional más justa y democrática.

La memoria, como el género, tiene, en definitiva, el poder y la responsabilidad de transformar. Recordar para construir un futuro que se olvide de discriminar.

\section{Bibliografía}

Amnistía Internacional. (2010). Comisionar la justicia. Comisiones de la verdad y justicia penal. Madrid: Publicaciones Amnistía internacional. Recuperado de http://www.iccnow. org/documents/pol300042010es_1.pdf

Arango, L. G., León, M. y Viveros, M. (1995). Introducción. En L. G. Arango, Balaguer, A. Una aproximación al potencial transformador de la justicia transicional desde una perspectiva feminista. (Tesis doctoral inédita). Institut Universitari de Drets Humans, Universitat de Valencia, España.

Balcells. Génere i racisme: més enllà de la doble discriminació. Universitat de Barcelona. Departament d'Antropologia Social. Grup de Recerca en Exclusió i Controls Socials.

Barsalou, J., Baxter, V. (2007). The urge to remember. The role of memorials in Social Reconstruction and Transitional Justice. Stabilization and Reconstruction. Series $n^{\circ} 5$. United States: Institute for Peace.
Beltrán, E., Maquieira, V., Álvarez, S. y Sánchez, C. (2001). Feminismos: debates teóricos contemporáneos. Madrid: Alianza Editorial.

Benavides, F. (2011). Justicia en épocas de transición. Conceptos, modelos, debates, experiencias. Barcelona: Institut Català Internacional per la Pau.

Bickford, L. (1999). The Archival Imperative: Human Rights and Historical Memory in Latin America's Southern Cone. Human Rigths Quarterly, 21(4), 1097-1122.

Bickford, L. (2007). Unofficial truth projects. Human Rights Quarterly. 29(4), 994-1035.

Bourque, S. C., Scott, J. W. (1996). El concepto de género en Lamas. En L. Marta (Comp.). El género: la construcción cultural de la diferencia sexual. México: Porrúa, PUEG-unam.

Brett, S., Bickford, L., Sevcenko, L. y Rios, M. (2007). Memorialization and Democracy: State Policy and Civic Action. Santiago de Chile: FLACSO, ICTJ y The International Coalition of Historic Site Museum of Conscience.

Carabí, A. (2003). Construyendo nuevas masculinidades: la representación de la masculinidad en la literatura y el cine de los Estados Unidos (1980-2003). (Memoria de proyecto de investigación). Ministerio de Trabajo y Asuntos Sociales, Instituto de la Mujer EXP. 62/03. Recuperado de http://www.ub.edu/ filoan/memmasc.pdf 
Cifuentes, M. R. (Enero-diciembre, 2009). La investigación sobre género y conflicto armado. Eleuthera, 3, 127-164.

El Jack, A. (2003). Género y conflictos armados. Informe general BRIDGE. Serie Canasta Básica. Londres: Institute of Development Studies.

Engle, K. (Octubre, 2005). Feminism and Its (Dis) contents: Criminalizing Wartime Rape in Bosnia and Herzegovina. The American Journal of International Law, 99(4), 778-816. Recuperado de http://www.jstor.org/stable/3396669

Fondo de Desarrollo de las Naciones Unidas para la Mujer. (2011). La memoria histórica desde una perspectiva de género. Recuperado de http://www.centrodememoriahistorica. gov.co/descargas/informes2011/la_reconstruccion_de_la_memoria_historica_desde_ la_perspectiva_de_genero_final.pdf

Galtung, J. (1998). Tras la violencia, 3r: reconstrucción, reconciliación, resolución. Bilbao: Bakeaz y Guernika.

Gilmore, D. (2008). Culturas de la masculinidad. En A. Carabí y M. Josep Armengol (eds.). La masculinidad a debate. Barcelona: Icaria editorial.

Grupo de Memoria Histórica. (2008). Trujillo, una tragedia que no cesa. Bogotá: Editorial Planeta.

Grupo de Memoria Histórica. (2009). El Salado. Esa guerra no era nuestra. Bogotá: Editorial Taurus.
Grupo de Memoria Histórica. (2010). La Rochela. Memorias de un crimen contra la justicia. Bogotá: Editorial Taurus.

Grupo de Memoria Histórica. (2011). Mujeres que hacen historia. Tierra, cuerpo y política en el Caribe colombiano. Bogotá: Ediciones Aguilar.

Grupo de Memoria Histórica. (2012). El Placer. Mujeres, coca y guerra en el Bajo Putumayo. Bogotá: Editorial Santillana.

Guzmán, D. (2011). Justicia transicional y género: un acercamiento desde las mujeres. Bogotá: Universidad Nacional de Colombia, Facultad de Derecho.

Guzmán, D., Uprimny, R. (2010). Justicia transicional desde abajo y con perspectiva de género. Bogotá: Fondo de Desarrollo de las Naciones Unidas para la Mujer, Unifem.

Jelin, E. (2002). Los trabajos de la memoria. Madrid: Siglo XXI.

Joinet, M. (1997). La cuestión de la impunidad de los autores de violaciones de los derechos humanos (derechos civiles y políticos). Informe final de la Subcomisión de prevención de discriminaciones y protección de las minorías. ONU/ECOSOC.

Kimmel, M. (2008). Los estudios de la masculinidad: una introducción. En A. Carabí y J. M. Armengol (eds.). La masculinidad a debate. Barcelona: Icaria editorial. 
Kiza, E., Corene, R. y Holger-C., R. (2006). Victims o War. An Empirical Study on War-Victimization and Victims' Attitudes Towards Addressing Atrocities. Hamburg: Hamburg Institute for Social Resarch.

Lamas, M. (1996). El género: la construcción cultural de la diferencia sexual. México: Programa Universitario de Estudios de Género, UNAM.

Lefranc, S. (2005). Políticas de perdón. Bogotá: Norma.

Lefranc, S. (2007). La eficacia de la justicia de transición. En El legado de la verdad: impacto de la justicia transicional en la construcción de la democracia en América Latina. Lecciones para Colombia. Serie Enfrentando el pasado. Bogotá: Centro Internacional para la Justicia Transicional.

León, M., Viveros, M. (Comps.). Género e identidad. Ensayo sobre lo femenino y lo masculino. Bogotá: Facultad de Ciencias Humanas de la Universidad Nacional de Colombia.

Leverenz, D. (2008). Varones de novela. En A. Carabí y J. M. Armengol (eds.). La masculinidad a debate. Barcelona: Icaria editorial.

Lozano, C. A. (2009). Justicia para la dignidad. La opción por los derechos de las víctimas. Bogotá: Unión Europea.

Mersky, M. (2007). El legado de la verdad: algunas reflexiones. En El legado de la verdad: impacto de la justicia transicional en la cons- trucción de la democracia en América Latina. Lecciones para Colombia. Serie Enfrentando el pasado. Bogotá: Centro Internacional para la Justicia Transicional.

Mohanty, C. T. (1998). Feminist Encounters: Locating the Politics of Experience. En A. Philips (ed.). Feminism and Politics, Oxford readings in feminism. Oxford: Oxford University Press.

Naidu, E. (August, 2006). The ties that bind: strengthening the links between memorialisation and transitional justice. TJP Research Brief. Centre for the Study of Violence and Reconciliation.

Programa de las Naciones Unidas para el Desarrollo. (2005). Mujer y conflicto armado. Revista Hechos del Callejón. Recuperado de http://www.mediosparalapaz.org/index. php?idcategoria=2153. 2006-09-21.

Rivera, M-M. (1994). Nombrar el mundo en femenino. Pensamiento de las mujeres y teoría feminista. Barcelona: Icaria.

Rubin, G. (1996). El tráfico de mujeres: notas sobre la "economía política" del sexo. En M. Lamas (comp.). El género: la construcción cultural de la diferencia sexual. México: Programa Universitario de Estudios de Género, unam.

Sánchez, G. (coord.). (2011). La memoria histórica desde una perspectiva de género. Conceptos y herramientas. Bogotá: cNRR, Grupo de Memoria Histórica. 
Santander, P. (2011). Por qué y cómo hacer análisis del discurso. Valparaíso: Pontificia Universidad Católica en Valparaíso. Recuperado de www.moebio.uchile.cl/41/santander.html

Scott, J. (1996). El género: una categoría útil para el análisis histórico. En M. Lamas. El género: la construcción cultural a la diferencia sexual (pp. 265-302). México: PUEG.

Segal, L. (2008). Los hombres tras el feminismo: ¿Qué queda por decir? En Carabí, À., Armengol, J. M. (eds.). La masculinidad a debate. Barcelona: Icaria editorial.

Shepard, B. (2001) Prefacio. Sobre las identidades masculinas. En M. Viveros Vigoya, J. Olavarría, N. Fuller (Comps.). Hombres e identidades de género. Investigaciones desde América Latina. Bogotá: ces, Universidad Nacional de Colombia.

Truñó, M. (2010). Reflexiones sobre la categoría de víctima de violencia política con mirada de género. Informes 02/2010. Barcelona: Institut Catalá Internacional per la Pau. Recuperado de http://www20.gencat.cat/docs/icip/Continguts/Publicacions/Documents\%20i\%20 informes/Arxius/Genere_informes2010_02. pdf

Uprimny Yepes, M. P., Saffón Sanín, C., Botero, M. y Restrepo Saldarriaga, E. (2006). ¿Justicia transicional sin transición? Verdad, justicia y reparación para Colombia. Bogotá: Centro de Estudios de Derecho, Justicia y Sociedad.
Uribe, M. T. (2007). El legado de la verdad: una lección para Colombia. En El legado de la verdad: impacto de la justicia transicional en la construcción de la democracia en América Latina. Lecciones para Colombia. Serie Enfrentando el pasado. Bogotá: Centro Internacional para la Justicia Transicional.

van Dijk, T. A. (1999). El análisis crítico del discurso. Anthropos (Barcelona), 186, septiembre-octubre 1999, pp. 23-36 http://cmap. upb.edu.co/rid=1J59CGKZN-84TOXK-C2/ analisisCriticodelDiscurso.pdf

Vañó, R. (2009). La construcción de pau en el Dret Internacional: una auditoría de género. (Treball d'investigació doctoral). València: Institut Universitari de Drets Humans, Universitat de València.

Viveros, M. (2001). Masculinidades. Diversidades regionales y cambios generacionales en Colombia. En V. Mara, O. José y F. Norma. Hombres e identidades de género. Investigaciones desde América Latina. Bogotá: CES, Universidad Nacional de Colombia.

Viveros, M., Olavarría, J., Fuller, N. (2001). Hombres e identidades de género. Investigaciones desde América Latina. Bogotá: CEs, Universidad Nacional de Colombia.

Wilches, I. (2012). Paz con género femenino. Investigación sobre mujeres y construcción de paz. Bogotá: Programa de las Naciones Unidas para el Desarrollo - onu Mujeres. 
Wills, M. E. (2009). Historia, memoria, género: trayectoria de una iniciativa y aprendizajes. En ¿Justicia desigual? Género y derechos de las víctimas en Colombia, Bogotá: Fondo de Desarrollo de las Naciones Unidas para la Mujer.

Wills, M. E. (Mayo-agosto, 2005). Mujeres en armas: ¿avance ciudadano o subyugación femenina? Análisis Político, 54, 63-81.
Zajovic, S. (2005). Encarar el pasado y justicia transicional: un enfoque feminista. Experiencias en Serbia. Ponencia en el encuentro de la Red Internacional de Mujeres de Negro. Jerusalén, 12 al 16 agosto de 2005. Recuperado de http://antimilitaristas.org/spip. php?article1972\&var_recherche=Stasa $\% 20$ Zajovic 